\title{
High Voltage Gain Multi-port Bidirectional DC-DC Converter with an Effective Multi-loop Control Strategy for PV/Battery Integrated Systems
}

\author{
Murat Mustafa Savrun ${ }^{1 *}$ (D), Alihan Atay ${ }^{2}$ \\ 1 Adana Alparslan Türkeş Science and Technology University, Department of Electrical \& Electronics Engineering, 01250, Adana, Turkey \\ ${ }^{2}$ Solvaytech Engineering Industry and Trade LTD. Co., Adana, Turkey
}

\begin{abstract}
This study proposes a novel isolated bidirectional multi-port converter (MPC) based on a switched-capacitor converter and a half-bridge converter with an effective control scheme for photovoltaic (PV) powered and battery buffered systems. The proposed power electronics converter interface integrates the converters to the ports which are connected with a battery coupled common DC busbar and high-frequency transformer (HFT). Thus, the three-port converter is formed without any need for an additional converter to regulate battery power flow. In addition, to transfer power from a low voltage PV energy unit to the battery and load, a single switch DC-DC converter with high voltage gain is proposed. The power flow between the ports is controlled by an effective multi-loop control scheme that is able to perform a smooth transition between the loops. In order to validate the viability and effectiveness of the proposed MPC, a proof-of-concept simulation model has been developed with a $3 \mathrm{~kW}$ PV and $220 \mathrm{~V} 12$ Ah battery. The performance of the proposed converter has been analyzed for different case studies, including dynamic operating and loading conditions.
\end{abstract}

Keywords: Multi-port DC-DC converter, switched-capacitor, photovoltaic, battery, multi-loop controller

\section{INTRODUCTION}

\subsection{Overview}

In the last few decades, the use and depletion of fossil fuels have accelerated in parallel with the significant increase in electricity demand [1]. The environmental concern and depletion of fossil fuels have led to develop renewable energy sources (RESs) powered clean applications such as electric vehicles [2], microgrids [3], residential grid-tie inverters [4]. Besides, RESs generating power in DC form are able to integrate with DC loads used in DC microgrids, which have become widespread in recent years, without using additional inverter devices [5]. Although RESs are good candidates for the aforementioned applications because of such advantages, they are by nature unstable in their availability and capacity [6]. The instantaneous production values of RESs vary with natural conditions such as solar irradiation/temperature [7], hydrogen pressure/temperature [8], and wind speed [9]. RES-based energy systems are frequently equipped with energy storage units in order to eliminate the non-linear behavior drawback of RESs. Battery units make it possible to provide uninterrupted power to loads by buffering fluctuations and interruptions of RESs.
The power flow between the RE- based energy unit, battery unit, and load is performed using power electronics converter interfaces. Traditionally, individual converters are employed and controlled in a decentralized manner to regulate the power flow [10]. Because of that, traditional RES-powered systems have high computational loads and costs. To overcome the aforementioned limitations, multi-port converters (MPC) are used, wherein RES-based energy units, battery units, and loads are connected to different ports of the MPC.

\subsection{Literature Survey}

MPCs are emerging power electronics solutions in order to integrate multi-inputs/outputs with combined functionalities and control schemes. MPCs can be divided into two categories as isolated and non-isolated converters and are presented in [11-13]. Non-isolated topologies have advantages such as simpler structure and compactness by the lack of a high-frequency transformer whereas they are not able to provide isolation and flexible voltage range [14]. On the other hand, isolated MPCs provide flexible voltage ranges via HFT turns ratio as well as isolation between the ports.
* Corresponding author

Email: msavrun@atu.edu.tr
European Mechanical Science (2021), 5(3): 99-104

doi: https://doi.org/10.26701/ems.934248

Received: May 7, 2021

Accepted: June 1, 2021 
Isolated MPCs are good candidates for RES powered and battery buffered systems because of their flexibility in performing power flow between the different ports.

Several isolated MPC topologies have been presented in the literature to integrate multi-input/output ports. Many studies have addressed isolated MPCs using the derivations of bridge converters that have capabilities of bidirectional power flow, galvanic isolation, zero-voltage switching, and zero-current switching [15]. Among the derivations of bridge converters, full-bridge converters have advantages of two times higher output voltage and higher power transfer capability, while half-bridge topologies with fewer switching devices are advantageous in relatively low power applications [16]. The turns ratio of HFTs makes it possible to provide flexibility in voltage conversion ratio, while the high turns ratio raises the problem of low efficiency. Therefore, MPCs that are endowed with low turns ratio HFTs and integrated with high gain converters stand out as in [7]. The power flow path at the MPC port where RESs are connected is designed to be unidirectional due to the nature of RESs. Because of that, RESs are equipped with unidirectional DC-DC converters. Various unidirectional high gain DC-DC converter topologies developed and applied in literature are reviewed in [17]. Step-up DC-DC converters temporarily store low voltage input energy on magnetic field storage components and transfer it to the output in high voltage levels [17]. The fundamental step-up converter is the traditional boost converters which have a restricted voltage gain with high output voltage ripple. In order to eliminate the output voltage ripples, interleaved topologies have been proposed [18]. Furthermore, multi-leg/multi-phase interleaved [19, 20], capacitor clamped h-bridge [21], and tristate boost converter [22] topologies are employed in order to further decrease the output voltage ripple and to improve the voltage conversion ratio. However, the related topologies have a limited gain and many active switching devices. The coupled inductor topologies make it possible to provide high voltage gain, but relatively large current ripples decay the service life of the connected port RES or battery unit [21]. Tang et al. [23] proposed a hybrid switched inductor converter. The switched inductor topology has a high voltage gain. However, the voltage stress on the diodes is the main drawback of the related topology.

\subsection{Key Contributions}

Literature review reveals the current researches focused on MPCs in order to integrate multi-input/output ports with reduced switches and complexity. In addition, it is concluded that the unidirectional DC-DC converters that have a high voltage conversion ratio to extract maximum power from RESs play a critical role for RES-powered systems. Among the related DC-DC converter topologies, switched-capacitor boost converter and half-bridge converter excel with the aforementioned advantages.

This paper proposes a new MPC that is equipped with switched-capacitor DC-DC converter in order to integrate RES with an isolated DC-DC converter via a battery coupled common busbar. Since an additional DC-DC converter that regulates the power flow of the battery contributes significantly to the size and cost of the overall system, the power flow of the battery is regulated by the existing converters considering operation conditions. The proposed system is equipped with a multi-loop control structure that operates adaptively and allows instantaneous switching between the loops. In order to validate the viability and effectiveness of the proposed system, different load and temperature scenarios are operated.

The pattern of this study is organized as follows: the power circuit configuration of the proposed system is given in $\mathrm{Se}$ ction 2. In Section 3, the operation modes of the proposed MPC and overall control scheme are explained in detail. Performance analysis and case studies are investigated and discussed in Section 4. Finally, conclusions are presented in Section 5.

\section{POWER CIRCUIT CONFIGURATION OF THE PROPOSED CONVERTER}

The power circuit configuration of the proposed MPC which is illustrated in Figure 1 consists of a half-bridge converter, a controlled full-wave rectifier, a switched-capacitor DC-DC converter, and a secondary center-tapped high-frequency transformer (HFT). The proposed converter interface is purposed to integrate battery, PV, and load and supervise the optimal power flow between input and output ports. Proposed MPC

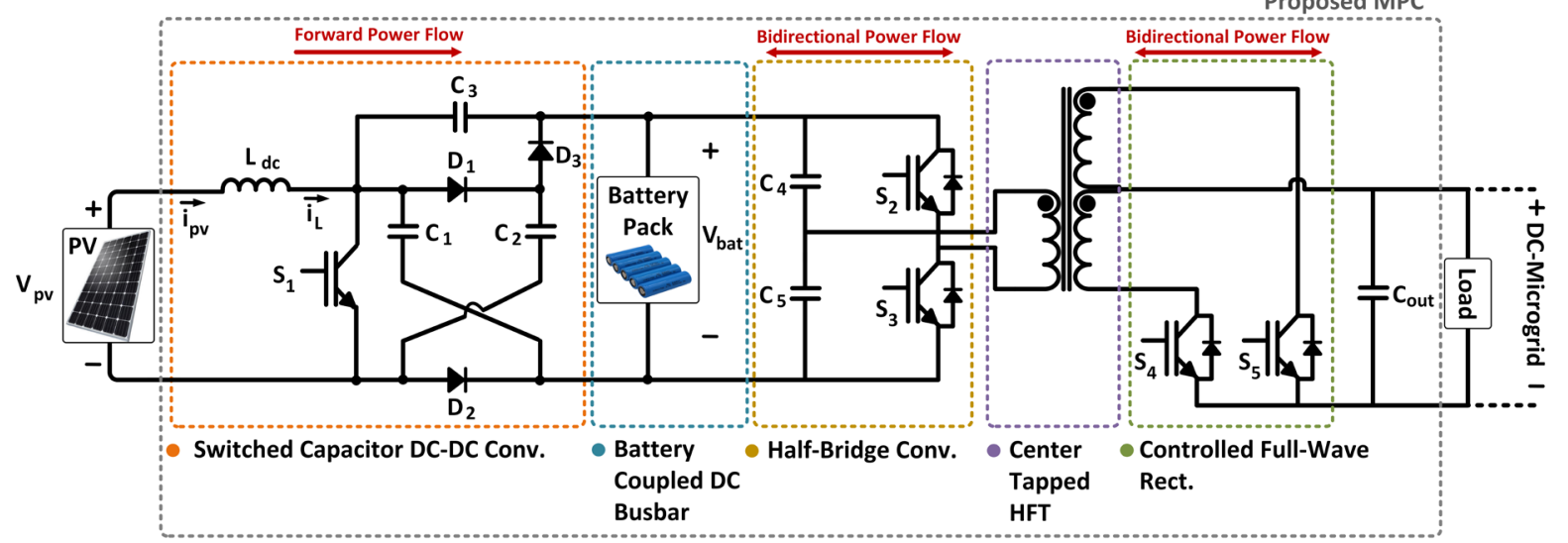

Figure 1. Circuit design of the proposed MPC 
The switched-capacitor DC-DC converter is used to transfer power from PV to the battery/load with high efficiency. Besides, the related DC-DC converter makes it possible to connect low voltage PV into a relatively high voltage battery due to its high voltage conversion ratio capability. Half-bridge converter allows bidirectional power flow by transferring power from input ports to the output port and from the output port to the battery. While the half-bridge converter operates as an inverter during forward power flow, it operates as an uncontrolled full-wave rectifier during reverse power flow. The galvanic isolation between the input and output ports is provided by HFT with low turns ratio. The controlled full wave rectifier located on the secondary side, on the contrary to the half-bridge converter, operates as an uncontrolled full-wave rectifier during the forward power flow and operates as an inverter during reverse power flow.

The proposed MPC integrates three different converters; (i) the switched-capacitor DC-DC converter, (ii) the half-bridge converter, and (iii) the controlled full-wave rectifier via battery coupled common DC busbar and HFT. On the primary side, while the battery operates as a common DC bus, the switched-capacitor DC-DC converter performs the maximum power point tracking, constant current $(\mathrm{CC})$, and constant voltage $(\mathrm{CV})$ charging methods. The DC-busbar of the half-bridge converter is fed by PV and buffered by battery. Thus, uninterrupted power transfer to the load is provided. The relationship between the PV and battery voltages is computed using the duty cycle of $S_{1}$. It is expressed as follows [24, 25];

$$
\text { Gain }=\frac{V_{b a t}}{V_{p v}}=\frac{2}{1-D}
$$

where $V_{b a t}$ and $V_{p v}$ represent the battery voltage and PV output voltage, respectively. $D$ describes the duty cycle of switch $S_{1}$ and varies between 0-1 considering operation conditions of the system.

\section{CONTROL SCHEME OF THE PROPOSED CONVERTER}

The detailed control structure is shown in Figure 2. The main aims of the overall controller scheme are: (i) to ensure the continuity of the power transfer to the load with constant DC-link voltage, (ii) to transfer excessive power produced by PV to the battery, (iii) to provide bidirectional power flow between the ports. The effective control structure for the proposed MPC is a multi-loop control structure that is composed of power flow management, MPPT, CC/CV charging, and DC-link control. The system operates adaptively and allows instantaneous switching between the control loops.

The optimal power flow between input energy units and the output load with respect to the instantaneous PV generation, charge characteristics of the battery, and load variations are the main part of the proposed converter operation. According to the instantaneous states of the ports, there are three possible power flow circumstances as mode1, mode 2, and mode 3 . Mode 1 corresponds to power transfer towards

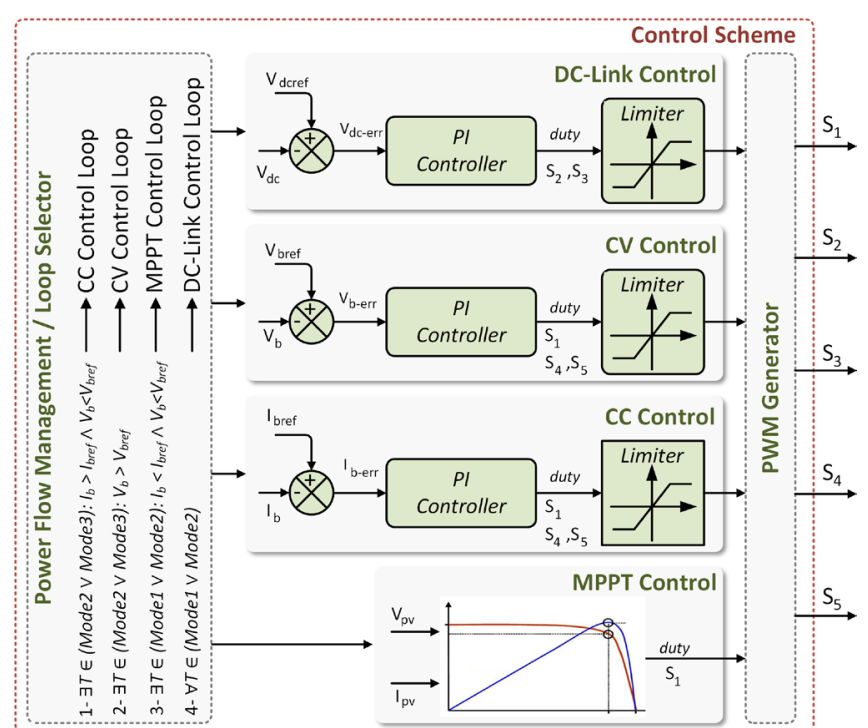

Figure 2. Control scheme of the proposed MPC

the load via PV and battery. In this mode, the battery operates in discharging mode. In mode 2, PV feeds the load, whereas the battery is charged via PV. Mode 3 represents the reverse power flow that is towards from the load side to the battery. In this mode, the battery operates in charging mode.

In mode 1 , the power of the load is provided from the PV and battery at the same time. There are two potential circumstances in this case. The primary condition may take place when the load power consumption is higher than the available PV power. In this time interval, the battery buffers the PV to transfer uninterrupted power to the load. The secondary condition is that the PV operates under rated power due to environmental situations such as irradiation (i.e. the generated power of PV decreases with irradiation reduction). The analytical relationship between power flows is given in $\mathrm{Eq}(2)$.

$$
\int_{t_{0}}^{t_{1}} P_{\text {load }}(t) d t=\int_{t_{0}}^{t_{1}} P_{p v}(t) d t+\int_{t_{0}}^{t_{1}} P_{b a t}(t) d t
$$

In mode 2, the PV supplies battery, and the load, namely the power produced by PV feeds the load and charges the battery at the same time. This situation may occur under low load consumption ratings. The PV power could be decreased when the low power is consumed. However, in cases where the PV generation is insufficient to supply the load, the battery must be charged to keep the DC-link voltage constant by buffering the PV. In cases where the battery state of charge is less than $100 \%$, the excessive power of the PV is used to charge the battery. During this time interval, power flows are expressed mathematically in Eq (3).

$$
\int_{t_{1}}^{t_{2}} P_{\text {load }}(t) d t=\int_{t_{1}}^{t_{2}} P_{p v}(t) d t-\int_{t_{1}}^{t_{2}} P_{\text {bat }}(t) d t
$$

In mode 3 , the battery is charged from the load side. This case may occur under a condition where there is no solar irradiation and the battery is charged by the $\mathrm{DC}$-microgrid to which the load is connected. By this way, the power flowing through the PV is zero. The power flow for this state is expressed as below: 


$$
\int_{t_{2}}^{t_{3}} P_{\text {load }}(t) d t=\int_{t_{2}}^{t_{3}} P_{b a t}(t) d t \quad \& \quad \int_{t_{2}}^{t_{3}} P_{p v}(t) d t=0
$$

The power transfer towards the load is performed using the DC-link control loop continuously, while the latter control loops are enabled considering the instantaneous power production value of PV. The power transfer from the load side to the battery is performed using $\mathrm{CC} / \mathrm{CV}$ charging algorithms. The common aspect of the aforementioned control loops is the use of the pulse width modulation (PWM) method. The duty cycle values of the switches regulate the power flow rating by adjusting the voltages of output DC-link and battery coupled DC busbar.

The DC-link control loop is used to regulate the output DC-link voltage by triggering $\mathrm{S}_{2}$ and $\mathrm{S}_{3}$ switching devices. The duty cycles of switches $S_{2}$ and $S_{3}$ with a $180^{\circ}$ phase shift between each other varies within the limits of 0-50 \%. A duty cycle of more than $50 \%$ causes the relevant switches to open simultaneously and short circuit. The duty cycles of the switches are computed using a PI controller. The difference between the reference $\left(V_{\text {dcref }}\right)$ and actual voltages $\left(V_{d c}\right)$ of the output load is applied to the PI controller.

The MPPT control loop is activated during mode 1 and some states of mode 2. The MPPT control loop is used to extract maximum power from PV by triggering the $\mathrm{S}_{1}$ switching device. The maximum power tracking is performed by the perturb and observe (P\&O) MPPT method due to the ease of operation and reduced computational load. The controller monitors the output voltage $\left(V_{p v}\right)$ and current $\left(I_{p v}\right)$ of PV and computes the instantaneous available power. The algorithm perturbs the operating voltage to ensure maximum power by adjusting the duty cycle of switch $S_{1}$. The operating voltage perturbation is performed by computing the instantaneous duty cycle of $S_{1}$ switch as follows;

$$
\begin{aligned}
& \left.D_{\text {new }}=D_{\text {old }}+\Delta D \quad \text { (if } P>P_{\text {old }}\right) \\
& \left.D_{\text {new }}=D_{\text {old }}-\Delta D \quad \text { (if } P<P_{\text {old }}\right) \\
& \left.D_{\text {new }}=D_{\text {old }} \quad \text { if } P=P_{\text {old }}\right)
\end{aligned}
$$

The available excessive power of PV is crucial in enabling one of the MPPT or CC control loops. The battery charging scenario has great importance to improve the service life of the battery. Therefore, the battery charge current is frequently is restricted with $0.5 \mathrm{C}$ (C represents the nominal capacity of the battery) charging current. Considering the charging current limits of the battery, the related cont- rol loops are enabled. If the battery charge current reaches the charge current limit, the MPPT control loop switches to the $\mathrm{CC}$ control loop. The $\mathrm{CC}$ control loop rises the battery voltage to its reference value of $242 \mathrm{~V}$. The $\mathrm{CV}$ control is enabled following the completion of the described operation of the CC loop. The $\mathrm{CV}$ charging continuous until the charging current gradually decreases to $0.05 \mathrm{C}$. The $\mathrm{CC} / \mathrm{CV}$ charging is achieved by adjusting the duty cycle of the switch $\mathrm{S}_{1}$. In addition, the CC/CV control loops are also enabled in mode 3 , which is another power transfer state towards to battery. The duty cycle value of the $\mathrm{S}_{1}$ switch is computed using PI controllers during related control loops are enabled. The CC control loop computes the duty cycle by using the error value between the reference $\left(I_{\text {bre }}\right)$ and actual $\left(I_{b}\right)$ values of the battery current while the $\mathrm{CV}$ control loop computes the duty cycle by using the error value between the reference $\left(V_{b r e}\right)$ and actual $\left(V_{b}\right)$ values of the battery voltage.

\section{PERFORMANCE ANALYSIS}

In this section, to verify the effectiveness and viability of the proposed MPC and the controller, a $3 \mathrm{~kW}$ proof-of-concept model which consists of $3 \mathrm{~kW} \mathrm{PV}$ and $220 \mathrm{~V} 12$ Ah battery has been developed using MATLAB/Simulink. The parameters of the simulation model are shown in Table 1 . The performance of the proposed system is tested under two case

\begin{tabular}{|c|c|c|}
\hline System & Parameters & Value \\
\hline \multirow{6}{*}{ PV } & PV maximum power $\left(1000 \mathrm{~W} / \mathrm{m}^{2}\right)$ & $3197 \mathrm{~W}$ \\
\hline & Maximum Power Point Voltage $\left(1000 \mathrm{~W} / \mathrm{m}^{2}\right)$ & $87 \mathrm{~V}$ \\
\hline & Maximum Power Point Current $\left(1000 \mathrm{~W} / \mathrm{m}^{2}\right)$ & $36.75 \mathrm{~A}$ \\
\hline & PV maximum power $\left(250 \mathrm{~W} / \mathrm{m}^{2}\right)$ & $801.3 \mathrm{~W}$ \\
\hline & Maximum Power Point Voltage $\left(250 \mathrm{~W} / \mathrm{m}^{2}\right)$ & $86.9 \mathrm{~V}$ \\
\hline & Maximum Power Point Current $\left(250 \mathrm{~W} / \mathrm{m}^{2}\right)$ & $9.221 \mathrm{~A}$ \\
\hline \multirow{3}{*}{ Battery } & Battery Capacity & $12 \mathrm{Ah}$ \\
\hline & Battery Nominal Voltage & $220 \mathrm{~V}$ \\
\hline & Battery Maximum Charge Current & $6 \mathrm{~A}$ \\
\hline \multirow{4}{*}{$\begin{array}{l}\text { Switched } \\
\text { Capacitor }\end{array}$} & Inductor $\left(\mathrm{L}_{\mathrm{dc}}\right)$ & $1 \mathrm{mH}$ \\
\hline & Capacitor $\left(C_{1}\right)$ & $250 \mathrm{uF}$ \\
\hline & Capacitor $\left(\mathrm{C}_{2}\right)$ & $250 \mathrm{uF}$ \\
\hline & Capacitor $\left(\mathrm{C}_{3}\right)$ & $500 \mathrm{uF}$ \\
\hline \multirow{5}{*}{ General } & Half Bridge Capacitors $\left(\mathrm{C}_{4}, \mathrm{C}_{5}\right)$ & $2 \mathrm{mF}$ \\
\hline & DC-Link Capacitor (Cout) & $1 \mathrm{mF}$ \\
\hline & Nominal DC-Link Voltage & 200 \\
\hline & Switching Frequency & $20 \mathrm{kHz}$ \\
\hline & HFT Turns Ratio & $1: 2: 2$ \\
\hline
\end{tabular}
studies including all modes of operations. The case studies which are summarized in Table 2 are formed by varying the irradiation of PV and loading.

Table 2. Details of case studies

\begin{tabular}{|c|c|c|c|c|c|c|}
\hline & \multicolumn{3}{|c|}{ Case 1 } & \multicolumn{3}{c|}{ Case 2 } \\
\cline { 2 - 6 } & \multicolumn{3}{|c|}{ Time Intervals } \\
\hline Time & $0-0.25 \mathrm{~s}$ & $0.25-0.5 \mathrm{~s}$ & $0.5-0.75 \mathrm{~s}$ & $0.75-1 \mathrm{~s}$ & $0-0.25 \mathrm{~s}$ & $0.25-0.5 \mathrm{~s}$ \\
\hline Irradiation & $300 \mathrm{~W} / \mathrm{m}^{2}$ & $650 \mathrm{~W} / \mathrm{m}^{2}$ & $1000 \mathrm{~W} / \mathrm{m}^{2}$ & $1000 \mathrm{~W} / \mathrm{m}^{2}$ & - & - \\
\hline Celcius & $25 \mathrm{C}^{\circ}$ & $25 \mathrm{C}^{\circ}$ & $25 \mathrm{C}^{\circ}$ & $25 \mathrm{C}^{\circ}$ & - \\
\hline DC-Link Demand & $1500 \mathrm{~W}$ & $1500 \mathrm{~W}$ & $1500 \mathrm{~W}$ & $1500 \mathrm{~W}$ & $-2000 \mathrm{~W}$ & $-2000 \mathrm{~W}$ \\
\hline Battery Charge/Discharge & Discharge & Charge & Charge (CC) & Charge (CV) & Charge (CC) & Charge (CV) \\
\hline Mode & Mode 1 & Mode 2 & Mode 2 & Mode 2 & Mode 3 & Mode 3 \\
\hline
\end{tabular}




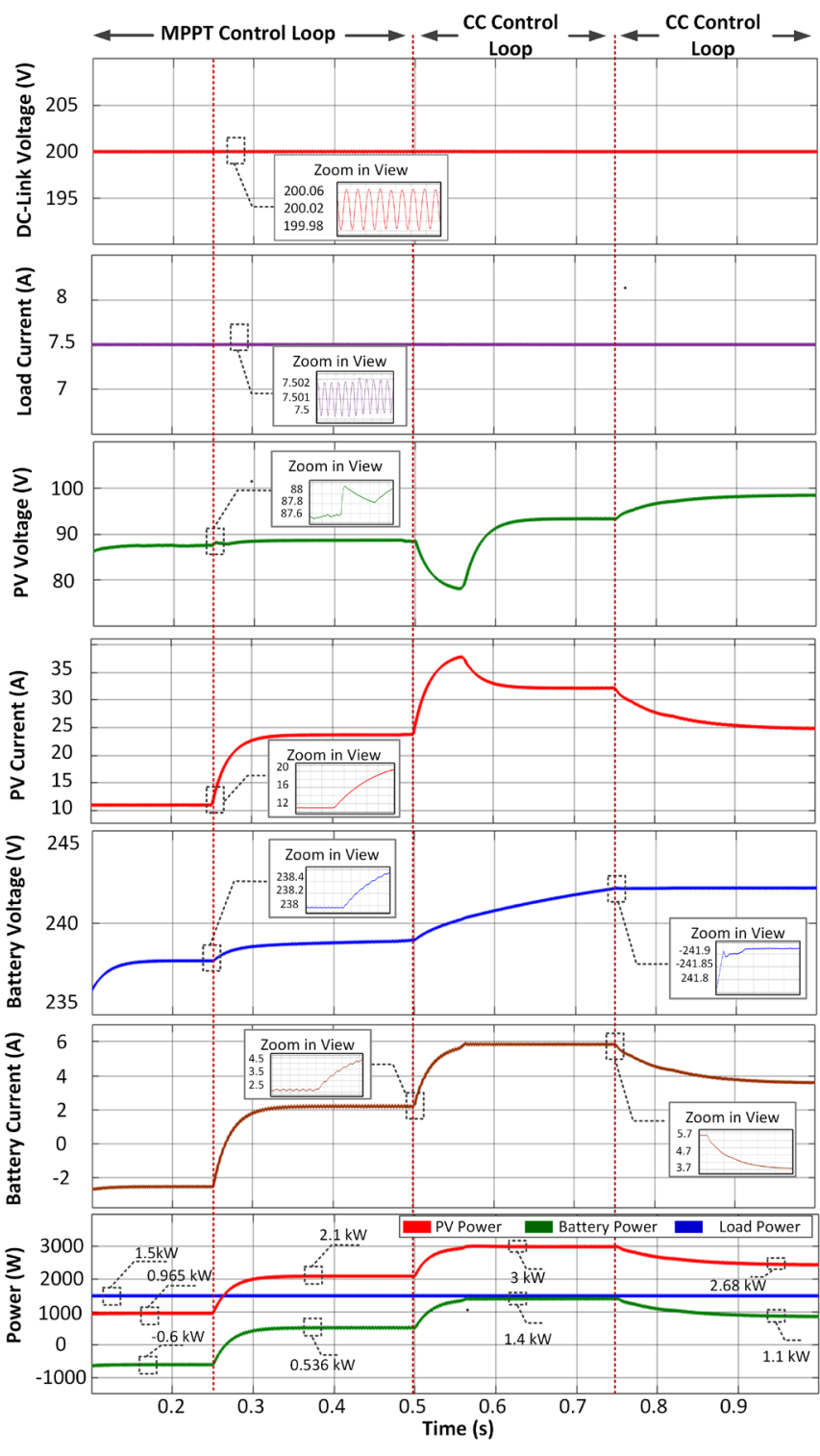

Figure 3. Performance results for case 1

The first case includes operating conditions in which mode 1, mode 2, and all control loops (MPPT, CC, CV, DC-link) are active, as well as the state responses of the transitions between these modes and loops. The different time intervals correspond to different operation modes and active control loops. Figure 3 shows the steady-state and dynamic responses of the proposed system during loop and mode transitions. It can be seen from the results that when the instantaneous power value of PV is lower than the load demand, the battery buffers and provides uninterrupted power to load. Following the raise in irradiation, the battery switches to charging in parallel with the increase in instantaneous power value of PV. During the state that the PV has relatively low output power, the MPPT control loop regulates the power flow from PV and the battery is charged with excessive power. However, in the case of high power generation from PV, the CC control loop is activated and the battery current is restricted. Following the battery voltage reaches a certain value, the $\mathrm{CV}$ control loop begins and keeps the output voltage of PV at a certain value. It is seen that the power of PV is increased to $1 \mathrm{~kW}, 2 \mathrm{~kW}$, and $3 \mathrm{~kW}$ with the raise in irradiation, while the battery is first discharged and then charged to the maximum voltage value.

The second case represents mode 3 operation in which the battery is charged by the DC microgrid. Figure 4 shows the steady-state and dynamic responses of the proposed converter during reverse power flow conditions. In this case study, the battery is charged with a constant current during the time interval of 0-0.5 s. The charge current of the battery is adjusted by the CC control loop. The CC charging is followed by $\mathrm{CV}$ charging during the time interval of 0.5-1 s.

The performance waveforms highlight that the proposed MPC and controller smoothly regulates the steady-state and transient power-sharing during different irradiation and loading variations. Besides, the efficiency of the proposed converter has been also evaluated. As can be seen from Figure $3-4$, the efficiency values considering the operating modes are $96 \%, 96.8 \%$, and $90 \%$, respectively. The efficiency values of the proposed converter show its effectiveness under all possible power flow conditions.

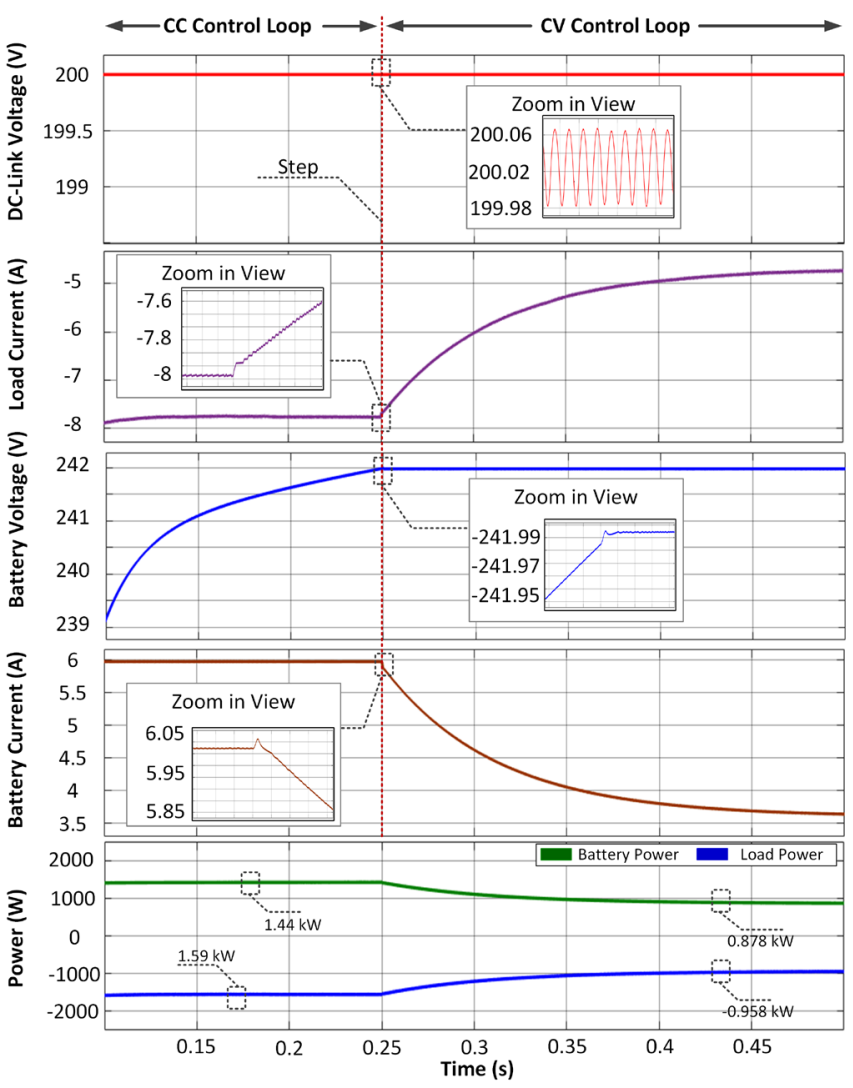

Figure 4. Performance results for case 2

\section{CONCLUSION AND DISCUSSION}

This study proposes a novel isolated bidirectional multi-port converter (MPC) based on a switched-capacitor converter and a half-bridge converter with an effective control scheme. The main advantages of the proposed converter are as follows: (i) low voltage PV integration with high voltage gain and high-efficiency switched-capacitor DC-DC converter, (ii) battery integration without an additional converter, (iii) reduced switch topology, (iv) cost-effectiveness (v) bidirectional power flow capability. The effectiveness of the propo- 
sed MPC is evaluated under various operating conditions. The results show that the proposed MPC performs all the aforementioned functionalities. In addition to its satisfactory performance under steady-state conditions, it provides effective power transfer with smooth transitions between control loops during transient conditions.

\section{REFERENCES}

[1] Das, M., Agarwal, V. (2016). Design and Analysis of a High-Efficiency DC-DC Converter With Soft Switching Capability for Renewable Energy Applications Requiring High Voltage Gain. IEEE Transactions on Industrial Electronics, 63: 2936-2944. doi:10.1109/ TIE.2016.2515565.

[2] Shen, D., Lim, C.-C., Shi, P. (2020). Robust fuzzy model predictive control for energy management systems in fuel cell vehicles. Control Engineering Practice, 98: 1-12. doi: 10.1016/j.conengprac.2020.104364.

[3] Naidu, B. R., Panda, G., Siano, P., (2018). A Self-Reliant DC Microgrid: Sizing, Control, Adaptive Dynamic Power Management, and Experimental Analysis. IEEE Transactions on Industrial Informatics, 14: 3300-3313. doi: 10.1109/TII.2017.2780193.

[4] Gangatharan, S., Rengasamy, M., Elavarasan, R. M., Das, N., Hossain, E., Sundaram, V. M. (2020). A Novel Battery Supported Energy Management System for the Effective Handling of Feeble Power in Hybrid Microgrid Environment. IEEE Access, 8: 217391-217415. doi: 10.1109/ACCESS.2020.3039403.

[5] Prabhakaran P., Agarwal, V. (2020). Novel Four-Port DC-DC Converter for Interfacing Solar PV-Fuel Cell Hybrid Sources With Low-Voltage Bipolar DC Microgrids. IEEE Journal of Emerging and Selected Topics in Power Electronics, 8: 1330-1340. doi: 10.1109/ JESTPE.2018.2885613.

[6] Jiang, J., Gao, L., Jin, J., Luan, T. H., Yu, S., Xiang, Y. (2019). Sustainability Analysis for Fog Nodes With Renewable Energy Supplies. IEEE Internet of Things Journal, 6: 6725-6735. doi: 10.1109/JIOT.2019.2910875.

[7] Savrun M. M., Atay, A. (2020). Multiport bidirectional DC-DC converter for PV powered electric vehicle equipped with battery and supercapacitor. IET Power Electronics, 13:3931-3939. doi: 10.1049/ iet-pel.2020.0759.

[8] Savrun M. M., Inci, M. (2021). Adaptive neuro-fuzzy inference system combined with genetic algorithm to improve power extraction capability in fuel cell applications. Journal of Cleaner Production, 299:1-11. doi: 10.1016/j.jclepro.2021.126944.

[9] Sefa, I., Altin, N., Ozdemir, S., Kaplan, O. (2015). Fuzzy PI controlled inverter for grid interactive renewable energy systems. IET Renewable Power Generation, 9: 729-738. doi: 10.1049/iet-rpg.2014.0404.

[10] Vettuparambil, A., Chatterjee, K., Fernandes, B. G. (2021). A Multiport Converter Interfacing Solar Photovoltaic Modules and Energy Storage With DC Microgrid. IEEE Transactions on Industrial Electronics, 68: 3113-3123. doi: 10.1109/TIE.2020.2978709.

[11] Zhang, N., Sutanto, D., Muttaqi, K. M. (2016). A review of topologies of three-port DC-DC converters for the integration of renewable energy and energy storage system. Renewable and Sustainable Energy Reviews, 56: 388-401. doi: 10.1016/j.rser.2015.11.079.

[12] Bhattacharjee, A. K., Kutkut, N., Batarseh, I. (2019). Review of Multiport Converters for Solar and Energy Storage Integration. IEEE Transactions on Power Electronics, 34: 1431-1445. doi: 10.1109/ TPEL.2018.2830788.

[13] Khosrogorji, S., Ahmadian, M., Torkaman, H., Soori, S. (2016). Mul- ti-input DC/DC converters in connection with distributed generation units - A review. Renewable and Sustainable Energy Reviews, 66: 360-379. doi: 10.1016/j.rser.2016.07.023.

[14] Chaudhury T., Kastha, D. (2020). A High Gain Multiport DC-DC Converter for Integrating Energy Storage Devices to DC Microgrid. IEEE Transactions on Power Electronics, 35:10501-10514. doi: 10.1109/TPEL.2020.2977909.

[15] Savrun, M. M., Köroğlu, T., Tan, A., Cuma, M. U., Bayindir, K. Ç., Tümay, M. (2020). Isolated H-bridge DC-DC converter integrated transformerless DVR for power quality improvement. IET Power Electronics, 13: 920-926. doi: 10.1049/iet-pel.2019.0687

[16] Chakraborty S., Chattopadhyay, S. (2017). Minimum-RMS-Current Operation of Asymmetric Dual Active Half-Bridge Converters With and Without ZVS. IEEE Transactions on Power Electronics, 32: 51325145. doi: 10.1109/TPEL.2016.2613874.

[17] Forouzesh, M., Siwakoti, Y. P., Gorji, S. A., Blaabjerg, F., Lehman, B. (2017). Step-Up DC-DC Converters: A Comprehensive Review of Voltage-Boosting Techniques, Topologies, and Applications. IEEE Transactions on Power Electronics, 32: 9143-9178. doi: 10.1109/ TPEL.2017.2652318.

[18] Wu, H., Zhang, J., Qin, X., Mu, T., Xing, Y. (2016). Secondary-Side-Regulated Soft-Switching Full-Bridge Three-Port Converter Based on Bridgeless Boost Rectifier and Bidirectional Converter for Multiple Energy Interface. IEEE Transactions on Power Electronics, 31: 48474860. doi: 10.1109/TPEL.2015.2473002.

[19] Saadi, R., Hammoudi, M. Y., Kraa, O., Ayad, M. Y., Bahri, M. (2020). A robust control of a 4-leg floating interleaved boost converter for fuel cell electric vehicle application. Mathematics and Computers in Simulation, 167: 32-47. doi: 10.1016/j.matcom.2019.09.014.

[20] Thounthong P., Davat, B. (2010). Study of a multiphase interleaved step-up converter for fuel cell high power applications. Energy Conversion and Management, 51: 826-832. doi: 10.1016/j.enconman.2009.11.018.

[21] Bi, H., Wang, P., Che, Y. (2019). A Capacitor Clamped H-Type Boost DC-DC Converter With Wide Voltage-Gain Range for Fuel Cell Vehicles. IEEE Transactions on Vehicular Technology, 68: 276-290. doi: 10.1109/TVT.2018.2884890.

[22] Kapat, S., Patra, A., Banerjee, S. (2009). A Current-Controlled Tristate Boost Converter With Improved Performance Through RHP Zero Elimination. IEEE Transactions on Power Electronics, 24: 776-786. doi: 10.1109/TPEL.2008.2008994.

[23] Tang, Y., Fu, D., Wang, T., Xu, Z. (2015). Hybrid Switched-Inductor Converters for High Step-Up Conversion. IEEE Transactions on Industrial Electronics, 62: 1480-1490. doi: 10.1109/TIE.2014.2364797.

[24] Ismail, E. H., Al-Saffar, M. A., Sabzali, A. J. (2008). High Conversion Ratio DC-DC Converters With Reduced Switch Stress. IEEE Transactions on Circuits and Systems I: Regular Papers, 55: 2139-2151. doi: 10.1109/TCSI.2008.918195.

[25] İnci, M., Büyük, M., Savrun, M. M., Demir, M. H. (2021). Design and analysis of fuel cell vehicle-to-grid (FCV2G) system with high voltage conversion interface for sustainable energy production. Sustainable Cities and Society, 67: 1-12. doi: 10.1016/j.scs.2021.102753. 